https://doi.org/10.1007/s10694-021-01101-5

\title{
Correction to: The Implications of Post-Fire Physical Features of Cylindrical 18650 Lithium-Ion Battery Cells
}

Tal Nagourney (D), Electrical \& Electronics, Engineering Systems Inc. (ESi), Seattle, WA, USA

Jonathan Jordan (D), Electrical \& Electronics, Engineering Systems Inc. (ESi), Dallas, TX, USA

Laban Marsh (D), Electrical \& Electronics, Engineering Systems Inc. (ESi),

Conroe, TX, USA

Dennis Scardino, Fire \& Explosions, Engineering Systems Inc. (ESi), Conroe, $T X, U S A$

Brian M. May (D), Chemistry, Engineering Systems Inc. (ESi), Aurora, IL, $U S A$

Accepted: 4 February 2021/Published online: 5 March 2021

\section{Correction to: Fire Technology htps://doi.org/10.1 007/s 1 0694-020-01077-8}

Correction to: Fire Technology 2021 The Author(s), under exclusive licence to Springer Science + Business Media, LLC part of Springer Nature Manufactured in The United States https://doi.org/10.1007/s10694-020-01077-8

The original publication of the article unfortunately contained a mistake in Fig. 2c. Figure 2c was meant to have a negative sign within the black circle to demonstrate the negative contact for the $18650 \mathrm{Li}$-ion cell. The correct figure has been given below.

The original article has been corrected.

*Correspondence should be addressed to: Jonathan Jordan, E-mail: jgjordan@engsys.com The original article can be found online at https://doi.org/10.1007/s10694-020-01077-8. 

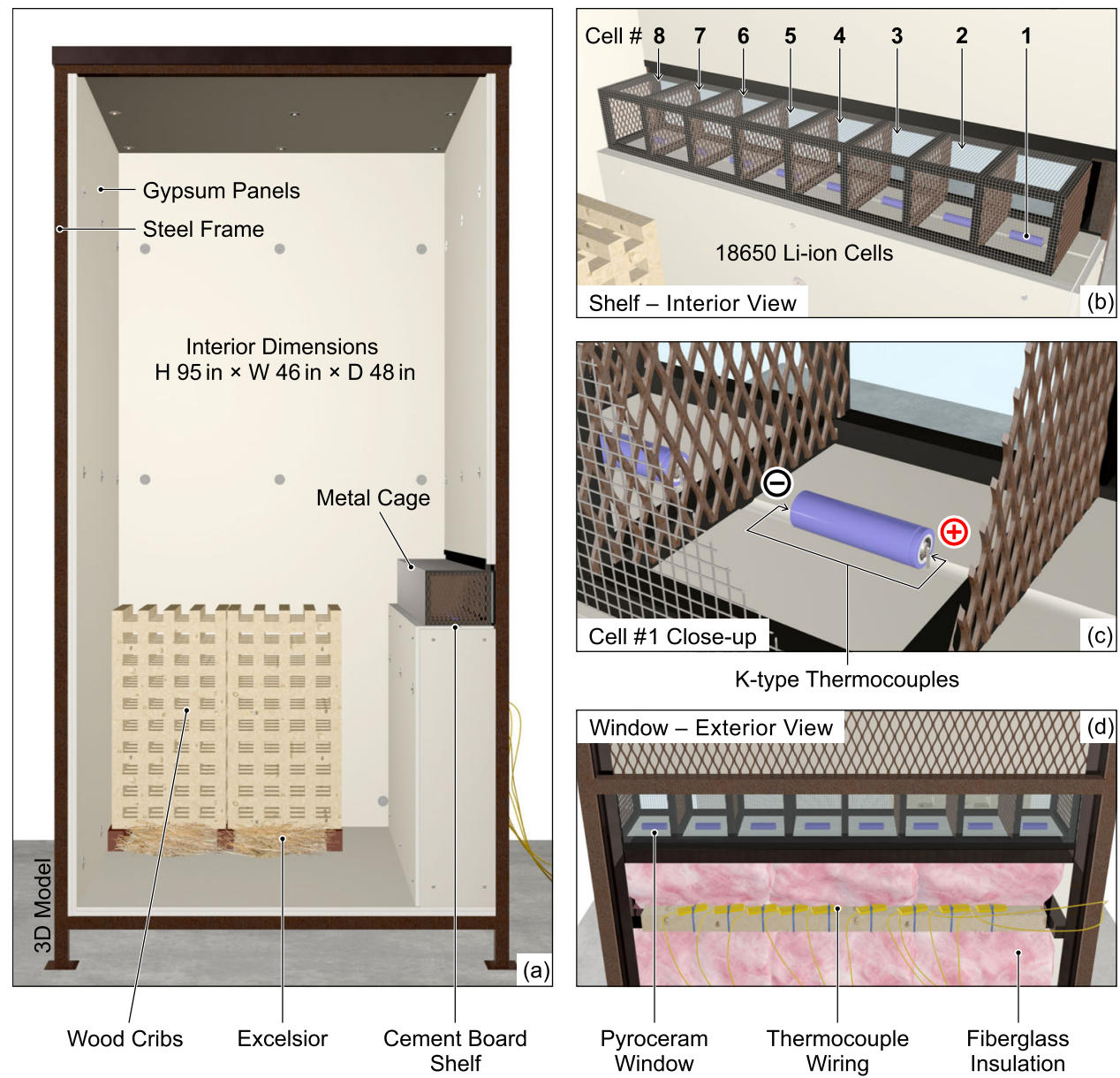

K-type Thermocouples

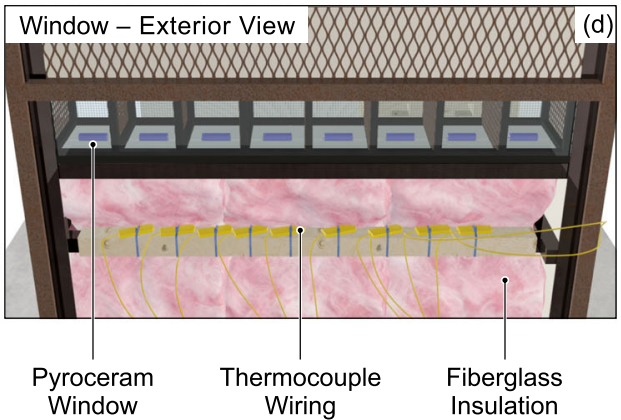

Figure 2. Diagrams of the fire test chamber. (a) Overview of the fire test chamber, front view. (b) Overview of the battery cells under test in their retention cages. (c) Detail of cell orientation and thermocouple placement. (d) Thermocouple routing and Pyroceram window. 